\title{
Employment of Two-Stage Oxygen Feeding to Control Temperature in a Downdraft Entrained-Flow Coal Gasifier
}

\author{
Ting Wang1, Xijia Lu', Heng-Wen Hsu' ${ }^{2}$, Cheng-Hsien Shen ${ }^{2}$ \\ ${ }^{1}$ Energy Conversion \& Conservation Center, University of New Orleans, New Orleans, LA, USA \\ ${ }^{2}$ Green Energy and Environment Research Laboratory, Industrial Technology Research Institute, Hsinchu City, \\ Taiwan \\ Email: twang@uno.edu, xlv@uno.edu, hsuhw@itri.org.tw, CHShen@itri.org.tw
}

Received 15 June 2014; revised 17 July 2014; accepted 20 August 2014

Copyright (C) 2014 by authors and Scientific Research Publishing Inc.

This work is licensed under the Creative Commons Attribution International License (CC BY). http://creativecommons.org/licenses/by/4.0/

(c) (i) 0 pen Access

\section{Abstract}

The traditional practice of employing a two-stage coal-fed gasification process is to feed all of the oxygen to provide a vigorous amount of combustion in the first stage but only feed the coal without oxygen in the second stage to allow the endothermic gasification process to occur downstream of the second stage. One of the merits of this 2-stage practice is to keep the gasifier temperature low downstream from the 2nd stage. This helps to extend the life of refractory bricks, decrease gasifier shut-down frequency for scheduled maintenance, and reduce the maintenance costs. In this traditional 2-stage practice, the temperature reduction in the second stage is achieved at the expense of a higher than normal temperature in the first stage. This study investigates a concept totally opposite to the traditional two-stage coal feeding practices in which the injected oxygen is split between the two stages, while all the coal is fed into the first stage. The hypothesis of this two-stage oxygen injection is that a distributed oxygen injection scheme can also distribute the release of heat to a larger gasifier volume and, thus, reduce the peak temperature distribution in the gasifier. The increased life expectancy and reduced maintenance of the refractory bricks can prevail in the entire gasifier and not just downstream from the second stage. In this study, both experiments and computational simulations have been performed to verify the hypothesis. A series of experiments conducted at 2.5 - 3.0 bars shows that the peak temperature and temperature range in the gasifier do decrease from $600^{\circ} \mathrm{C}-1550^{\circ} \mathrm{C}$ with one stage oxygen injection to $950^{\circ} \mathrm{C}$ $1230^{\circ} \mathrm{C}$ with a $60-40$ oxygen split-injection. The CFD results conducted at 2.5 bars show that 1 ) the carbon conversion ratio for different oxygen injection schemes are all above $95 \% ; 2$ ) $\mathrm{H}_{2}$ (about $70 \%$ vol.) dominates the syngas composition at the exit; 3 ) the $80 \%-20 \%$ case yields the lowest peak temperature and the most uniform temperature distribution along the gasifier; and 4) the $40 \%-60 \%$ case produces the syngas with the highest HHV. Both experimental data and CFD predictions verify the hypothesis that it is feasible to reduce the peak temperature and achieve more 
uniform temperature in the gasifier by adequately controlling a two-stage oxygen injection with only minor changes of the composition and heating value of the syngas.

\title{
Keywords
}

\author{
Two-Stage Oxygen Feeding, Entrained-Flow Coal Gasification, Gasification Simulation, \\ Syngas Composition, Clean Coal Technology, Multiphase Flow Simulation
}

\section{Introduction}

\subsection{Brief Review of Fuel Feeding Scheme of Entrained Coal Gasification}

Gasification is an incomplete oxidation process converting various carbon-based feedstocks into clean synthetic gas (syngas), which is primarily a mixture of hydrogen $\left(\mathrm{H}_{2}\right)$ and carbon monoxide (CO) with minor amounts of methane $\left(\mathrm{CH}_{4}\right)$ and inert nitrogen gas $\left(\mathrm{N}_{2}\right)$. There are four main classes of gasifiers: fixed bed gasifier, fluidized bed gasifier, entrained flow gasifier, and transport gasifier. The fixed bed gasifier and fluidized bed gasifier have low $\left(425^{\circ} \mathrm{C}-650^{\circ} \mathrm{C}\right)$ and moderate $\left(900^{\circ} \mathrm{C}-1050^{\circ} \mathrm{C}\right)$ outlet gas temperatures, respectively. Entrained flow gasifiers have high outlet temperatures $\left(1250^{\circ} \mathrm{C}-1600^{\circ} \mathrm{C}\right)$ and operate in the slagging range (the ash is fully liquid with low viscosity). The main benefits of entrained flow gasifiers can be summarized as: the ability to handle practically any coal as feedstock, syngas being free of oils and tars, high carbon conversion, suitable for synthesis gas products, and high throughput because of high reaction rates at elevated temperature.

According to the direction of the main flow inside the gasifiers, the entrained flow gasifiers can be classified as up-flow design such as the Shell SCGP and E-gas processes, and down-flow design such as the GE and Simmens gasifiers. For down-flow coal gasifier (GE gasifier), coal slurry and oxidant are introduced from the top of the gasifier. The hot raw gas produced during the gasification process flows toward the bottom of the gasifier. The ash forming components melt in the gasifier, flow down the walls of the reactor, and finally leave the reactor as a liquid slag.

Based on the fuel injection scheme, the entrained flow gasifiers can be categorized as single-stage injection and two-stage injection. The E-Gas process of ConocoPhillips features a two-stage up-flow gasifier design consisting of a horizontal cylindrical vessel as the first stage and a vertical cylindrical vessel as the second stage. Approximately $78 \%$ of the coal slurry and $100 \%$ of the oxygen are fed in the first stage. Additional coal-water slurry without oxygen is injected into this hot syngas in the second gasifier stage. Endothermic gasification reactions occur between the hot syngas and the second stage coal feed. This lowers the temperature of the syngas and increases the cold gas efficiency of the process. One of the most important advantages of this 2-stage practice is to keep the gasifier temperature low downstream from the 2nd stage and thus extends the life of the refractory bricks, decreases gasifier shut-down frequency for scheduled maintenance, and reduces maintenance costs. Although local stoichiometry as well as dynamic variations in the local stoichiometry will also affect corrosion of the refractory liner, this study only focuses on managing the temperature distribution.

\subsection{Motivation, Hypothesis, and Objectives}

Contrast to the traditional concept of two-stage coal feeding practices of injecting coal slurry into two different stages, it is hypothesized that splitting oxygen between two stages, while feeding all the coal in the first stage, i.e., a distributed oxygen injection scheme, can distribute heat release into a larger gasifier's volume and hence reduces the peak temperature and make temperature distribution more uniform in the gasifier. In this approach, the increased life expectancy and reduced maintenance of the refractory can prevail in the entire gasifier-not just downstream from the second stage as in the traditional two-stage coal slurry fed system. To verify this hypothesis, both experiments and computational simulations are conducted. Since conducting experiments are expensive, time consuming, and usually performed with limited cases, it would be more effective and meaningful to establish a computational fluid dynamics (CFD) model to simulate effects of varying operating conditions to help obtain a preliminary understanding of the fundamental thermal-flow physics inside the gasifier. However, since the coal gasification is a very complicated multi-component and multi-phase process, a trustful and fully calibrated 
computational model is not available. To obtain a usable computational model as a meaningful tool, the experimental data is utilized to guide interpretation of the computational result in low operating pressure (2.5 bars) cases. Afterwards, the computational model is employed to perform detailed thermal-flow and chemical reaction simulation for more parametric studies that have not been performed by experiments. To this end, the objectives of this paper are:

1) Conduct experiments to investigate the effect of a controlled two-stage distributed oxygen approach on a gasifier's inner wall temperature distribution.

2) Interpret the CFD results and determine how the results can be effectively used by comparing them with the baseline experimental data.

3) Use the CFD model to simulate experimental cases with different oxygen split fed from $100 \%$ to $40 \%$ under the condition of 2.5 bars and 0.6 stoichiometric ratio.

4) Investigate computationally the effect of distributed oxygen fed on gasification performance and temperature distribution under a higher operating pressure ( 25 bars) and 0.4 stoichiometric ratio.

\section{Experimental Facility}

Industrial Technology Research Institute (ITRI) has designed a 2 ton/day, two-stage coal slurry fed, down draft entrained-flow gasifier for this study, as shown in Figure 1. This experimental facility is located in the southern Taiwanese city of Kaohsiung. The height of the gasification section above the quench section is $4.831 \mathrm{~m}$, the inner diameter is $0.27 \mathrm{~m}$, and the thickness of the refractory is $0.35 \mathrm{~m}$. The coal powder is first mixed with water at a mass ratio of approximately $43 \%$ (coal) $/ 57 \%$ (water). The coal slurry is then transported through the center tube of the injector as shown in Figure 2. All the oxygen is fed through the outer concentric annular pipe and is

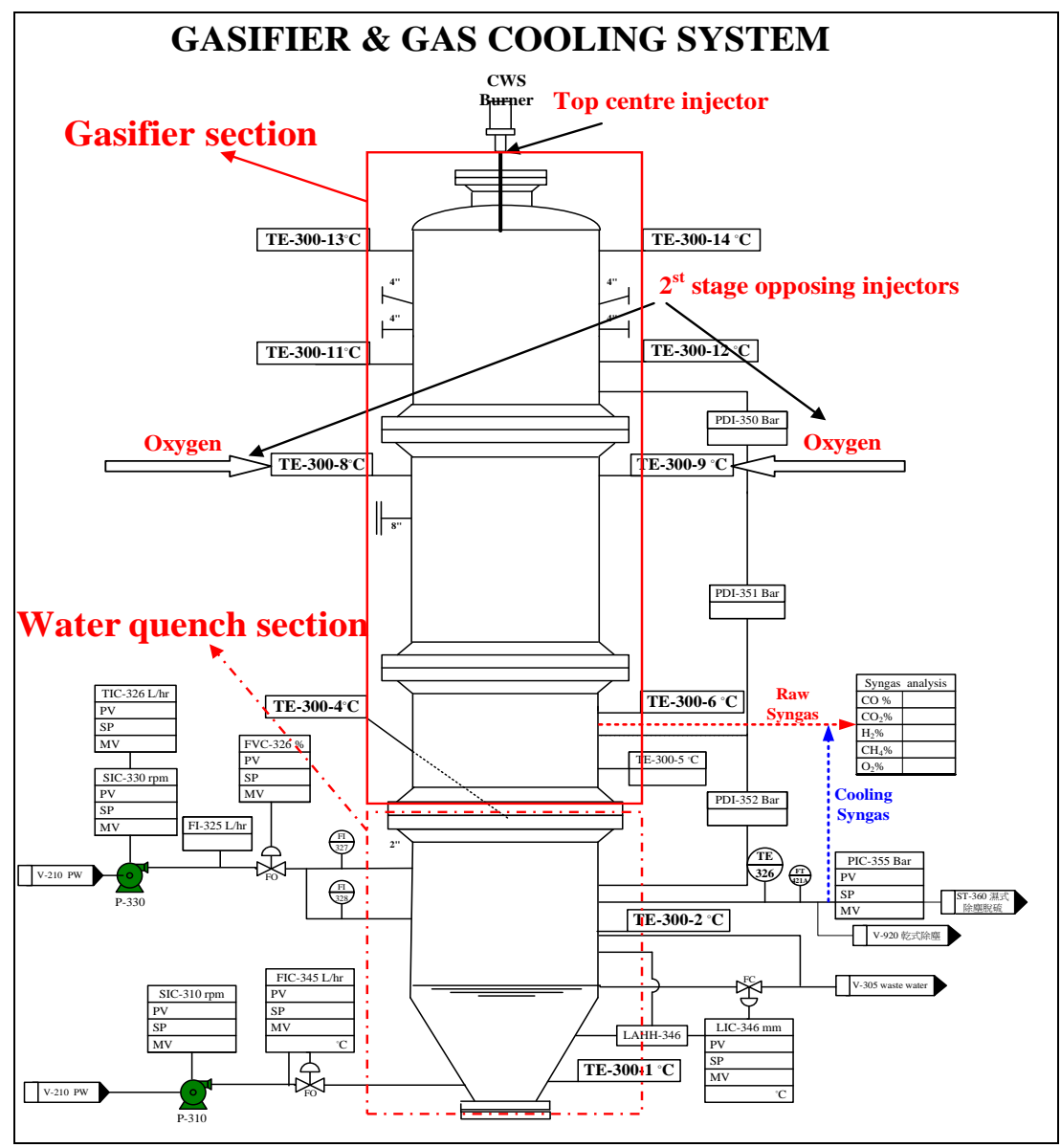

Figure 1. ITRI coal-slurry fed, oxygen blown, downdraft entrained-flow gasifier. The outline of the gasifier is based on the outside diameter of the refractory. 


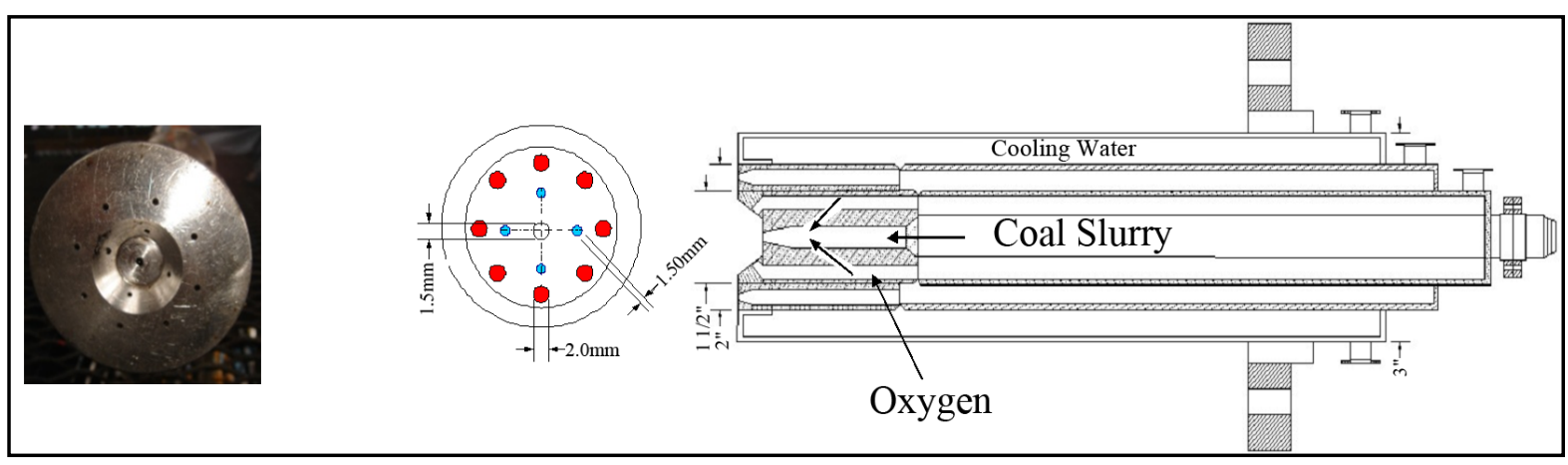

Figure 2. The internally premixed slurry-coal/oxygen injector with the coal-slurry fed in the center with oxygen fed through the concentric outer annular pipe.

mixed with the slurry coal before injection. The total oxygen fed to the gasifier is about $60 \%$ of the stoichiometric amount needed for complete coal combustion (i.e., with a stoichiometric ratio of 0.6). The injector is water cooled through an annular water jacket wrapping around the fuel and oxygen passages. The blunt injector tip with multiple holes is derived from a previous study which investigated the performance and life expectancy of two injectors' designs [1]. It was discovered that the injector with a blunt tip geometry was able to reduce temperature gradient along the injector and significantly increase the life of the fuel injector more than the injector with the conical tip. The injector used in this study is designed and manufactured for experimental use only with three options for feeding oxygen-via the outer eight holes or inner four holes for external mixing, or using premixing scheme as shown in Figure 2. In this study, premixing scheme is used and other holes are plugged.

The gas temperatures are sampled with thermocouples being placed in cavities recessing one-inch in the wall. The gasification process occurs in a down-drafted mode with the syngas exiting near the bottom of the gasifier and continuously entering the quenching section. A detailed discussion about the quench section has been documented in Wang et al. [2].

With the purpose of finding an optimum oxygen feeding ratio between injections from the top and a second location about 1/3 from the top of the gasifier, a series of experiments were conducted. The experiment is first conducted with $100 \%$ oxygen injected from the top, but it is discovered that the temperature is too high on the top and too cold in the middle section of the gasifier. Moreover, the carbon conversion ratio is poor, at around $72 \%$. To improve the temperature distribution and carbon conversion ratio, part of the oxygen up to 60\% (Figure 1), is diverted from the top injector to the side injectors in the middle section. This is done to hopefully provide more effective oxidation and hence more energy for feeding the gasification process in the middle section. The results are encouraging and show that the previous low temperatures in the middle and lower sections of the gasifier increased while the high temperature on the top reduced, resulting in a more uniform temperature distribution along the entire gasifier. More detailed analysis of the experimental results will be presented together with the computational results later.

\section{Computational Model}

\subsection{Global Gasification and Chemical Reactions}

This study deals with the global chemical reactions of coal gasification [3] that can be generalized in reactions (R1.1) through (R1.10) in Table 1.

In this study, the methanation reactions are not considered since the production of methane is negligible under the studied operating conditions. The volatiles are modeled to go through a two-step thermal cracking process (R7) and gasification processes (R8, R9) with $\mathrm{CH}_{4}$ or $\mathrm{C}_{2} \mathrm{H}_{2}$ as the intermediate products. The coal used in this study is Chinese Shanxi Pinghsuo coal, and its compositions are given in Table 2. The compositions of volatiles are derived from the coal's heating value, proximate analysis, and ultimate analysis.

For the reaction rate of water-gas shift (WGS) reaction (R5), Lu and Wang [8] [9] tested Jones' rate by comparing the syngas composition results with the experimental data and, due to the difference in operating pressure and other boundary conditions, they purposely reduce the rate constant to $\mathrm{A}=2.75$ to match the experimental data. Consequently, $\mathrm{A}=2.75, \mathrm{E}=8.38 \times 10^{7}$ is used for the WGS reaction rate in this paper. 
Table 1. Summary of reaction rate constants referenced in this study.

\begin{tabular}{|c|c|c|c|c|c|c|}
\hline & \multirow{2}{*}{ Reactions } & \multirow{2}{*}{ Reaction Type } & \multirow{2}{*}{$\begin{array}{l}\text { Reaction heat, } \\
\Delta \mathrm{H}_{\mathrm{R}}^{\circ} \\
(\mathrm{MJ} / \mathrm{kmol})\end{array}$} & \multicolumn{2}{|c|}{$\begin{array}{c}\mathrm{k}=\mathrm{AT}^{\mathrm{n}} \exp (-\mathrm{E} / \mathrm{RT}) \\
(\mathrm{n}=0)\end{array}$} & \multirow{2}{*}{ Reference } \\
\hline & & & & $A\left(s^{-1}\right)$ & $\mathrm{E}(\mathrm{J} / \mathrm{kmol})$ & \\
\hline \multicolumn{7}{|c|}{ Heterogeneous Reactions } \\
\hline R 1 & $\mathrm{C}(\mathrm{s})+1 / 2 \mathrm{O}_{2} \rightarrow \mathrm{CO}$ & Partial combustion & -110.5 & 0.052 & $6.1 \times 10^{7}$ & Chen et al. [4] \\
\hline R 2 & $\mathrm{C}(\mathrm{s})+\mathrm{CO}_{2} \rightarrow 2 \mathrm{CO}$ & $\begin{array}{c}\text { Gasification, } \\
\text { Boudouard reaction }\end{array}$ & +172.0 & 0.0732 & $1.125 \times 10^{8}$ & Chen et al. [4] \\
\hline R 3 & $\mathrm{C}(\mathrm{s})+\mathrm{H}_{2} \mathrm{O} \rightarrow \mathrm{CO}+\mathrm{H}_{2}$ & Gasification & +131.4 & 0.0782 & $1.15 \times 10^{8}$ & Chen et al. [4] \\
\hline \multicolumn{7}{|c|}{ Homogeneous Reactions } \\
\hline R 4 & $\mathrm{CO}+1 / 2 \mathrm{O}_{2} \rightarrow \mathrm{CO}_{2}$ & Combustion & -283.1 & $2.2 \times 10^{12}$ & $1.67 \times 10^{8}$ & $\begin{array}{l}\text { Westbrook and Dryer } \\
{[5]}\end{array}$ \\
\hline R 5 & $\mathrm{CO}+\mathrm{H}_{2} \mathrm{O}(\mathrm{g}) \leftrightarrow \mathrm{CO}_{2}+\mathrm{H}_{2}$ & Water Gas shift & -41.0 & $2.75 \times 10^{10 \#}$ & $8.38 \times 10^{7}$ & Jones and L indstedt [6] \\
\hline R 6 & $\mathrm{CO}+3 \mathrm{H}_{2} \leftrightarrow \mathrm{CH}_{4}+\mathrm{H}_{2} \mathrm{O}$ & Methanation & -205.7 & $\begin{aligned} \mathrm{k}_{\mathrm{f}} & =4.4 \times 10^{11} \\
\mathrm{k}_{\mathrm{b}} & =5.12 \times 10^{-14}\end{aligned}$ & $\begin{array}{l}1.68 \times 10^{8} \\
2.73 \times 10^{4}\end{array}$ & Benyon [7] \\
\hline R 7 & \multicolumn{2}{|c|}{$\begin{array}{l}\mathrm{CH}_{2.997} \mathrm{O}_{0.3456} \rightarrow 0.3456 \mathrm{CO}+0.1897 \mathrm{H}_{2}+ \\
0.6544 \mathrm{CH}_{4} \text { (Two-step Volatiles Cracking) }\end{array}$} & +12.088 & \multicolumn{2}{|c|}{ Eddy dissipation } & \\
\hline R 8 & \multicolumn{2}{|c|}{$\begin{array}{l}\mathrm{CH}_{4}+1 / 2 \mathrm{O}_{2} \rightarrow \mathrm{CO}+2 \mathrm{H}_{2} \\
\text { Volatiles gasification via } \mathrm{CH}_{4}\end{array}$} & -35.71 & \multicolumn{2}{|c|}{ Eddy dissipation } & N/A \\
\hline R 9 & \multicolumn{2}{|c|}{$\begin{array}{l}\mathrm{C}_{2} \mathrm{H}_{2}+\mathrm{O}_{2} \rightarrow 2 \mathrm{CO}+\mathrm{H}_{2} \\
\text { Volatiles gasification via } \mathrm{C}_{2} \mathrm{H}_{2}\end{array}$} & -447.83 & \multicolumn{2}{|c|}{ Eddy dissipation } & \\
\hline R 10 & $\mathrm{H}_{2}+1 / 2 \mathrm{O}_{2} \rightarrow \mathrm{H}_{2} \mathrm{O}$ & Oxidation & -242 & $6.8 \times 10^{15}$ & $1.68 \times 10^{8}$ & Jones and Lindstedt [6] \\
\hline
\end{tabular}

1) All $\Delta \mathrm{H}_{\mathrm{R}}^{\circ}$ at $298 \mathrm{~K}$ and $1 \mathrm{~atm} .2$ 2) “+” Endothermic (absorbing heat), “-” Exothermic (releasing heat). \# The value of A in [6] has been modified as 2.75 in this study.

Table 2. The proximate and ultimate analyses of Chinese Shanxi Pinghsuo coal.

\begin{tabular}{ccc}
\hline Coal & Pingshuo Coal \\
\hline Moisture & Proximate Analysis, wt $\%$ & \\
VM & 4.31 \\
Ash & 32.60 \\
Fixed Carbon & 13.52 \\
Higher Heating Value (HHV) (kcal/kg) & 49.57 \\
Moisture & 6612 \\
Ash & \\
C & 2.04 \\
H & 12.69 \\
N & 70.94 \\
S & 4.78 \\
O & 0.78 \\
\hline
\end{tabular}




\subsection{Computational Methodology}

The computational model and submodels (devolatilization, reactions, particle dynamics, gasification) used in the study are the same as developed by Silaen and Wang (2010) [10], as well as Lu and Wang (2013) [8] [9]. Therefore, the governing and associated equations and detailed modeling intricacies are not repeated here, but they are briefly summarized below.

The time-averaged steady-state 3-D Navier-Stokes equations as well as the mass and energy conservation equations are solved. Species transport equations are solved for all gas species involved. It is well known that turbulence modeling has always been a sensitive issue for flow simulations because each turbulence model usually works only for some specific flow behaviors and none of any turbulence model can predict all the flows with high fidelity. Since investigation of the effect of turbulence models on gasification process is not an objective of this study, selection of an appropriate turbulence model is guided by a previous research performed by Silaen and Wang [10]. They applied five turbulence models (standard k- $\varepsilon, \mathrm{k}-\omega$, RSM, $\mathrm{k}-\omega \mathrm{SST}$, and k- $\varepsilon$ RNG) and reported that the RSM model predicted the best results. However, the standard k- $\varepsilon$ turbulence model yields reasonable results without requiring significant computational time when compared to the more elegant RSM model. Therefore, the standard $k-\varepsilon$ turbulence model is used in this study to provide closure. Enhanced wall function and variable material property are used. The $\mathrm{P} 1$ model is used for computing the radiation effect.

The flow (continuous phase) is solved in Eulerian form as a continuum while the particles (dispersed phase) are solved in Lagrangian form as a discrete phase. Stochastic tracking scheme is employed to model the effects of turbulence on the particles. The continuous phase and discrete phase are communicated through drag forces, lift forces, heat transfer, mass transfer, and species transfer. The finite-rate combustion model is used for the heterogeneous reactions, but both the finite-rate and eddy-dissipation models are used for the homogeneous reactions, and the smaller of the two is used as the reaction rate. The finite-rate model calculates the reaction rates based on the kinetics while the eddy-dissipation model calculates based on the turbulent mixing rate of the flow. Gasification or combustion of coal particles undergoes the following global processes: 1) evaporation of moisture; 2) devolatilization; 3) gasification to CO and 4) combustion of volatiles, $\mathrm{CO}$, and char. The Chemical Percolation Devolatilization (CPD) model [11]-[13] is chosen as the devolatilization model based on the finding by Silaen and Wang (2010) [10] that the Kobayashi two-competing rates devolatilization model [14] is very slow while the CPD model gives a reasonable result.

For solid particles, the rate of depletion of the solid, due to a surface reaction, is expressed as a function of kinetic rate, solid species mass fraction on the surface, and particle surface area. The reaction rates are all global net rates, i.e., the backward reaction, calculated by equilibrium constants, are included in the global rate. Therefore, the finite rate employed in this study implicitly applies to the local equilibrium approach. Reaction rate constants used in this study are summarized in Table 1.

For liquid droplets, water evaporates from the particle's surface when the temperature is higher than the saturation temperature (based on local water vapor concentration). The evaporation rate is controlled by the water vapor diffusion from the droplet surface to the surroundings until $100 \%$ relative humidity is achieved. When the boiling temperature (determined by the air-water mixture pressure) is reached, water evaporation rate is controlled by the heat transfer rate at the droplet surface. After the moisture is evaporated, due to either high temperature or low moisture partial pressure, the vapor diffuses into the main flow and is transported away. Droplet breakup model and coalescence model have been applied for tracking the droplet movement. Please refer to Silaen and Wang [10] for details, which are not repeated here. Since this paper focuses on using an established CFD model and submodels to study the effect of distributed oxygen injection rather than develop a new model, no review of other research group's modeling efforts is conducted here.

\subsection{Computational Domains}

The computational domain and elements on the gasifier wall are shown in Figure 3. The computational domain contains roughly 1.1 million elements. A grid sensitivity study of 3-D geometries is conducted. Three different grids are used including a coarse grid (0.4 million cells), a medium grid (1.1 million cells), and a fine grid (1.6 million cells). The results of the temperature distribution along the gasifier show a difference of $7 \%$ between the coarse and medium grids and $2 \%$ between the medium and the fine grids. In order to save computational time, the medium grid of 1.1 million cells is chosen.

FLUENT 12.0.16 from ANSYS, Inc. is used as the CFD solver. The simulation is steady-state and uses the 


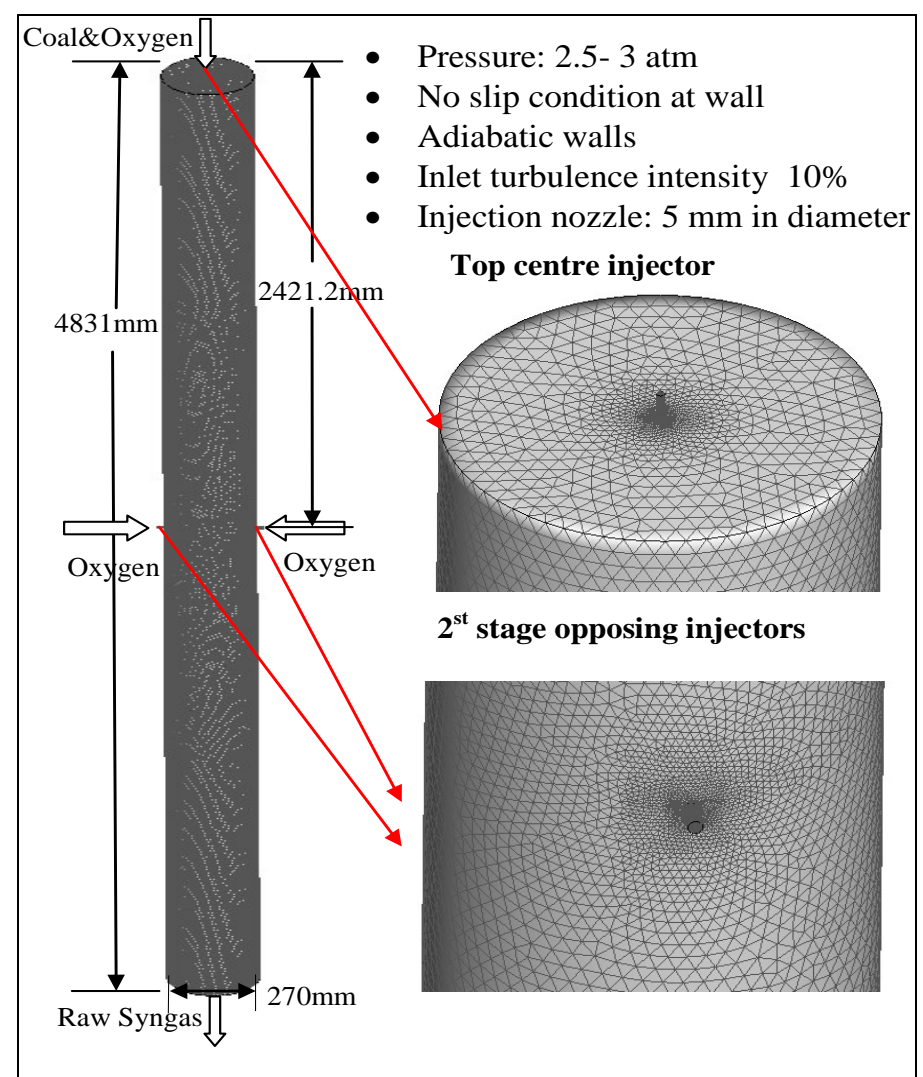

Figure 3. Meshed computational domain of the two-stage entrainedflow gasifier.

segregated solver, which employs an implicit pressure-correction scheme and decouples the momentum and energy equations. The SIMPLE algorithm is used to couple the pressure and velocity. Second order upwind scheme is selected for spatial discretization of the convective terms and species. For the finite rate model where the Eulerian-Lagrangian approach is used, the iterations are conducted alternatively between the continuous and the dispersed phases. Initially, two iterations in the continuous phase are conducted followed by one iteration in the discrete phase to avoid the flame from dying out. Once the flame is stably established, five iterations are performed in the continuous phase followed by one iteration in the dispersed phase. The drag, particle surface reaction, and mass transfer between the dispersed and the continuous phases are calculated. Based on the dispersed phase calculation results, the continuous phase is updated in the next iteration, and the process is repeated. Converged results are obtained when the residuals satisfy mass residual of $10^{-3}$, energy residual of $10^{-5}$, and momentum and turbulence kinetic energy residuals of $10^{-4}$. These residuals are the summation of the imbalance in each cell, scaled by a representative for the flow rate.

\subsection{Boundary and Inlet Conditions}

The summary of the studied cases is listed in Table 3. In Case 1, a two-stage configuration is used with oxygen distribution of $100 \%-0 \%$ between the top and the second stages. The coal is fed as slurry. The total mass flow rate of the coal slurry is $92 \mathrm{~kg} / \mathrm{hr}(0.026 \mathrm{~kg} / \mathrm{s})$, and the total volume flow rate of oxidant is $36.8 \mathrm{Nm} / \mathrm{s}(0.0146$ $\mathrm{kg} / \mathrm{s}$ ). The top and the second injection nozzles are both $5 \mathrm{~mm}$ in diameter. To match the experimental conditions, the operating pressure is set as 3 bars for Case 1 . From Case 2 to Case 8 , the oxygen distribution is $100 \%$ 0\%, $90 \%-10 \%, 80 \%-20 \%, 70 \%-30 \%, 60 \%-40 \%, 50 \%-50 \%, 40 \%-60 \%$ between the top and the second injection stages respectively. Total mass flow rate of the coal slurry is $85 \mathrm{~kg} / \mathrm{hr}(0.024 \mathrm{~kg} / \mathrm{s})$, and the total volume flow rate of oxidant is $38.6 \mathrm{Nm}^{3} / \mathrm{s}(0.0153 \mathrm{~kg} / \mathrm{s})$. The operating pressure is 2.5 bars for Cases 2 to 8 .

The above eight cases from $1-8$ are set up with the same operating conditions as the experiments. The following five cases from Cases 9 - 12 increase the operating pressure to 25 bars at which no experiments have been 
Table 3. Parameters and operating conditions of the studied cases.

\begin{tabular}{cccc}
\hline & Case 1 & Cases $2-8$ & Cases 9 - 12 (CFD only) \\
\hline $\mathrm{O}_{2}$ distribution (top-second) & $100 \%-0 \%$ & $(100 \%-0 \%)-(40 \%-60 \%)$ & $(100 \%-0 \%)-(40 \%-60 \%)$ \\
Coal slurry injection (kg/s) & 0.026 & 0.024 & 0.024 \\
$\mathrm{O}_{2}$ injection $(\mathrm{kg} / \mathrm{s})$ & 0.0146 & 0.0153 & 0.009216 \\
Operating pressure (bars) & 3.0 & 2.5 & 25 \\
\hline
\end{tabular}

conducted in the current facility. From Case 9 to Case 12, the oxygen distribution between the top and the second injection stages is $100 \%-0 \%, 80 \%-20 \%, 60 \%-40 \%, 40 \%-60 \%$ respectively. Total mass flow rate of the coal slurry is $85 \mathrm{~kg} / \mathrm{hr}(0.024 \mathrm{~kg} / \mathrm{s})$, and the total volume flow rate of the oxidant is $17.4 \mathrm{Nm}^{3} / \mathrm{s}(0.006912$ $\mathrm{kg} / \mathrm{s}$ ), which is $30 \%$ of the stoichiometric amount for complete combustion.

The oxidant is considered to be a continuous flow, and the coal particles are considered to be the discrete phase. The discrete phase includes the fixed carbon and liquid water droplets from both the inherent moisture content of coal (4.31\% wt) and the injected water content form the coal slurry (57.1\% wt). Other components of the coal, such as $\mathrm{N}, \mathrm{H}, \mathrm{S}, \mathrm{O}$, and ash, are injected as gas together with the oxidant in the continuous flow to keep the mass flow the same as in the experiments. $\mathrm{N}$ is treated as $\mathrm{N}_{2}, \mathrm{H}$ as $\mathrm{H}_{2}$, and $\mathrm{O}$ as $\mathrm{O}_{2}$. S and ash are not modeled, and their masses are lumped into $\mathrm{N}_{2}$. Since studying the effect of coal particle sizes on gasification performance is not in the objectives of this study, the coal slurry size is uniformly given as $50 \mu \mathrm{m}$ for the purpose of conveniently tracking the change of particle sizes. The effect of coal particle size on gasification process has been discussed in [5] and is not investigated in this study.

The walls are assigned as adiabatic with internal emissivity of 0.8 . In case of dry wall, interactions between the droplets and wall usually manifest three major phenomena, including reflect, break-up and trap. The actual phenomenon depends on the incoming Weber number of the droplet. Here, the Weber number is the ratio of kinetic energy of a droplet to the surface energy of a droplet $\left(W e=\rho d_{d} v_{d}^{2} / \sigma\right)$. If the Weber number $\left(\mathrm{We}_{\text {in }}\right)$ is less than 10 , the droplet will reflects elastically after it hits the wall. As the incoming We increases further to $\mathrm{We}_{\text {in }}>$ 80, the droplet falls into disintegration region which leads breaking-up the droplet to several small droplets. In the transition region of $30<\mathrm{We}<80$, the droplet has the chance to either reflect or breakup. In the case of this study, since the Weber number is less than 10, the boundary condition of the discrete phase at walls is assigned as "reflect", which means the discrete phase elastically rebound off once reaching the wall. At the outlet, the discrete phase simply escapes/exits the computational domain. An area near the coal injection locations is initially patched with temperature of $1500 \mathrm{~K}$ to simulate the ignition process of a real operation. The limit of the highest temperature is assigned as $5000 \mathrm{~K}$, and the limit of the lowest temperature is assigned as $400 \mathrm{~K}$. This will remove potential runaway conditions caused by erratic, unreasonably high, or low temperatures during the iteration process.

\section{Results and Discussions}

\subsection{Comparison between CFD Results and Experimental Data}

The computational cases 1 - 8 are conducted with the conditions matching those in the experiments. Among these eight cases, the detailed temperature and species distributions of Case 1 and Case 6 are exhibited to gain fundamental understanding of the thermal-flow behavior inside the gasifier. The conditions of these two cases are listed below.

- Case 1: Oxygen distribution (100\% - 0\%), coal slurry (92 kg/hr), oxidant (36.8 Nm $/ \mathrm{s}$ or $0.0146 \mathrm{~kg} / \mathrm{s})$, and operating pressure (3 bars).

- Case 6: Oxygen distribution (60\% - 40\%), coal slurry (85 kg/hr), oxidant (38.6 Nm³ $/ \mathrm{s}$ or $0.0153 \mathrm{~kg} / \mathrm{s})$, and operating pressure (2.5 bars).

\subsubsection{Case 1 ( $100 \%$ - 0\% for Oxygen Distribution)}

Case 1 is one stage oxygen-blown operation with the oxygen distribution being $100 \%$ - $0 \%$ between the top and the second stages. Gas temperature and species mole fraction distribution on the horizontal and selected center vertical planes in the gasifier are shown in Figure 4. Since all the fuel is injected from the top, the gas tempera- 
ture is higher in the top injection region than at the second stage location. Maximum gas temperature in the top injection stage reaches $2300 \mathrm{~K}$. The dominant reaction in the top injection stage is the intense char combustion $\left(\mathrm{C}+1 / 2 \mathrm{O}_{2} \rightarrow \mathrm{CO}\right.$ and $\left.\mathrm{CO}+1 / 2 \mathrm{O}_{2} \rightarrow \mathrm{CO}_{2}\right)$ as well as volatiles combustion via our 2-stage model in the first stage. Near the second stage, gasification reactions (mainly $\mathrm{C}+1 / 2 \mathrm{CO}_{2} \rightarrow \mathrm{CO}, \mathrm{C}+\mathrm{H}_{2} \mathrm{O} \rightarrow \mathrm{CO}+\mathrm{H}_{2}$ ) dominate. Due to the exothermic property of combustion process and endothermic property of the gasification reactions, the temperature drops gradually from top injection to the exit of the gasifier. Oxygen is completely depleted through the char combustion in the top injection region. The exit syngas composition calculated by CFD is shown in Table 4.

The mass-flow-rate weighted exit syngas temperature across over the entire exit section calculated by CFD is $1044 \mathrm{~K}$ and the near-wall average temperature is $986 \mathrm{~K}$. They are $90 \mathrm{~K}$ and $32 \mathrm{~K}$ higher than the measured data, respectively. Note that the gas temperature was too hot to be measured by thermocouple, so the experimental temperature data was measured by thermocouples placed in cavities in the wall. Thus, it is not intended to compare the measured temperatures with the simulated core gas temperatures, rather the measured data are used to provide a reference for comparing the local near-wall syngas temperature at $5 \mathrm{~mm}$ from the wall.

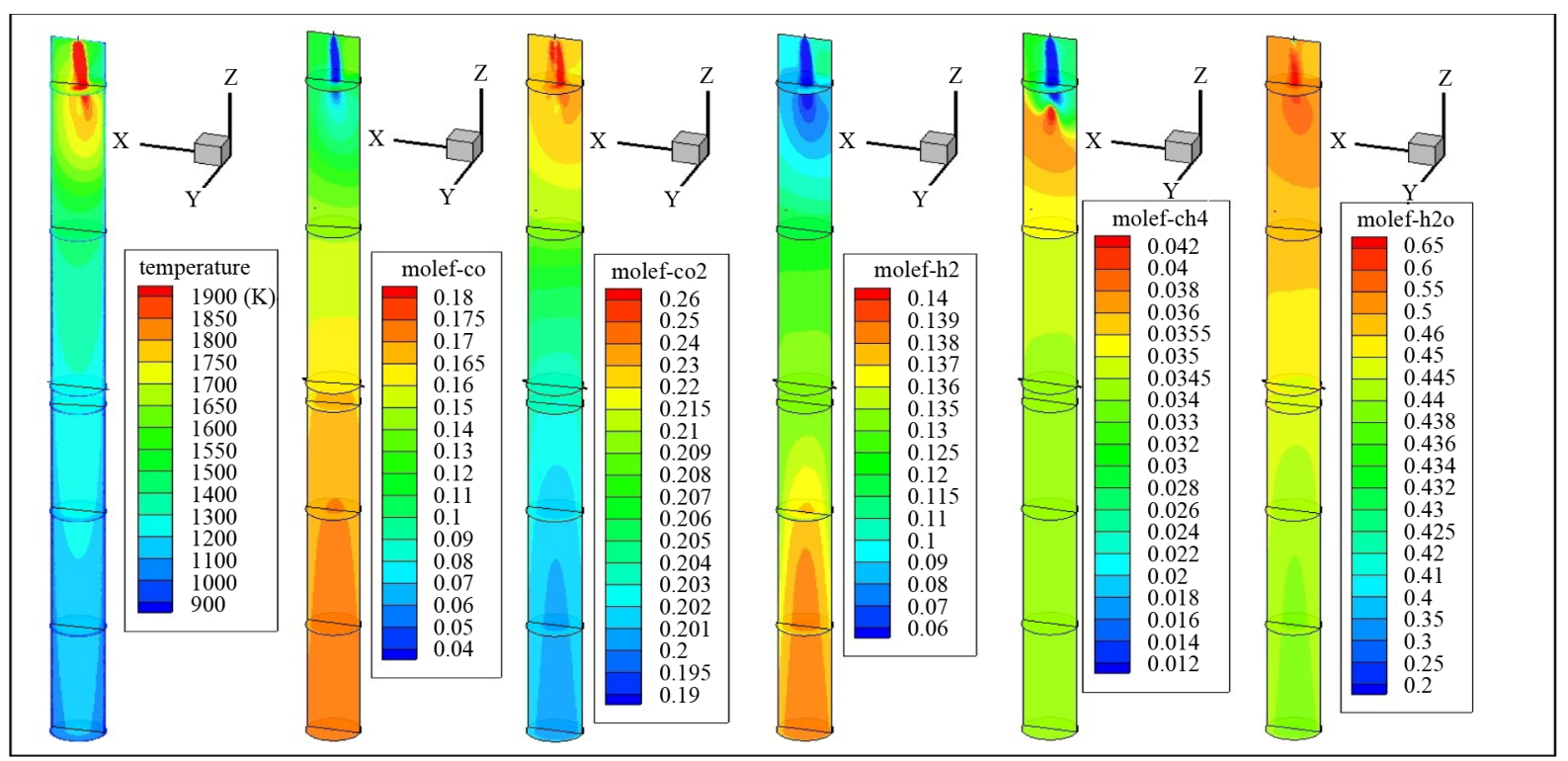

Figure 4. CFD simulated gas temperature and species mole fraction distributions for Case 1 (100\% - $0 \%$ for oxygen distribution).

Table 4. Exit syngas composition of CFD results for Cases 1 and 6 and comparison of near-wall syngas temperature with measured temperatures in a wall cavity.

\begin{tabular}{ccc}
\hline CFD syngas composition (Vol.) & Case 1 & Case 6 \\
$\mathrm{CO}$ & $17 \%$ & $22 \%$ \\
$\mathrm{CO}_{2}$ & $20 \%$ & $14 \%$ \\
$\mathrm{H}_{2}$ & $14 \%$ & $44 \%$ \\
$\mathrm{H}_{2} \mathrm{O}$ & $46 \%$ & $2 \%$ \\
$\mathrm{CH}_{4}$ & $3 \%$ & 1550 \\
$\mathrm{CFD} \mathrm{Temp} \mathrm{(K)}$ & & 1172 \\
Cross-section average & 1044 & 1150 \\
Near-wall average & 986 & 954 \\
Experi. Temp (K) in wall cavity
\end{tabular}


Therefore, the comparison indicates that the average cross-sectional gas temperature is about $90 \mathrm{~K}$ hotter than the wall temperature and the near-wall temperature is about $32 \mathrm{~K}$ higher than the wall temperature.

\subsubsection{Case 6 (60\% - 40\% for Oxygen Distribution)}

Case 6 is the two-stage oxygen-blown operation with oxygen distribution of $60 \%$ - $40 \%$ between the first and the second stages. Gas temperature and species mole fraction distribution on the horizontal and center vertical planes in the gasifier are shown in Figure 5. The gas temperature is higher at the second stage injection region than at the top injection region. Maximum gas temperature reaches $2600 \mathrm{~K}$ at the second stage injection location and $1900 \mathrm{~K}$ at the top injection stage. The dominant reaction near the top injection location is the intense char combustion ( $\mathrm{C}+1 / 2 \mathrm{O}_{2} \rightarrow \mathrm{CO}$ and $\mathrm{CO}+1 / 2 \mathrm{O}_{2} \rightarrow \mathrm{CO}_{2}$ ) as well as the volatiles oxidation via our two-stage model; then the endothermic gasification reactions occur in the region between the first and second stage injection locations as can be seen by increased $\mathrm{CO}$ and $\mathrm{H}_{2}$ but reduced temperature. WGS also occurs, evident by reduced $\mathrm{H}_{2} \mathrm{O}$. At the second stage injection location, unburned char, $\mathrm{CO}$ and $\mathrm{H}_{2}$ quickly react with injected oxygen from two sides and release the second wave of combustion/oxidation heat $\left(\mathrm{C}+1 / 2 \mathrm{O}_{2} \rightarrow \mathrm{CO}, \mathrm{CO}+1 / 2 \mathrm{O}_{2} \rightarrow \mathrm{CO}_{2}\right.$ and $\mathrm{H}_{2}+1 / 2 \mathrm{O}_{2} \rightarrow \mathrm{H}_{2} \mathrm{O}$ ). The gasification reactions dominate the process after the oxygen is completely consumed in the region between the second stage injection location and the gasifier's exit.

Figure 6 and Figure 7 show CFD cross-sectional and mid-plane plots of the velocity vector, contours of temperature and mole fraction of $\mathrm{CO}_{2}$ at the second injection stage for both Case $6(60 \%-40 \%$ for oxygen distribution) and Case 3 (90\% - 10\% for oxygen distribution) respectively. In Case 6, 40\% oxygen, which is injected from two opposing injectors at the second stage, squeezes the main flow laterally to both sides perpendicular to the injection direction (top and bottom of Figure 6(a) and Figure 6(b)). The contours of temperature and mole fraction of $\mathrm{CO}_{2}$ show that the chemical reactions are affected by the local flow behavior, which is demonstrated by the high temperature and $\mathrm{CO}_{2}$ concentration presented towards top and bottom in Figure 6(a) and Figure 6(b). In Case 3, only 10\% oxygen is injected at the second stage. The opposing injecting effect is not strong enough to block the main flow, so the combustion reaction only takes place below the second stage, which is shown by the contours of temperature and mole fraction of $\mathrm{CO}_{2}$ in Figure 7.

The CFD calculated temperature is shown in Table 4 by two values. The first value $(1550 \mathrm{~K})$ is the mass-flow-rate weighted average temperature over the cross-section on the exit plane, and the second value $(1172 \mathrm{~K})$ is the mass-flow-rate weighted average temperature in the near-wall region ( $5 \mathrm{~mm}$ to the wall). The near-wall temperature is comparable to the experimental data $(1150 \mathrm{~K})$ within $22 \mathrm{~K}$. Since the thermocouples were placed in cavities recessing in the wall, the measured data adequately reflects the relatively cooler syngas temperature near the wall. Figure 8 shows the temperature contour on the cross-section of the exit plane. It clearly shows that the temperature changes significantly from the center at around $2000 \mathrm{~K}$ to around $1150 \mathrm{~K}$ in the near-wall region.

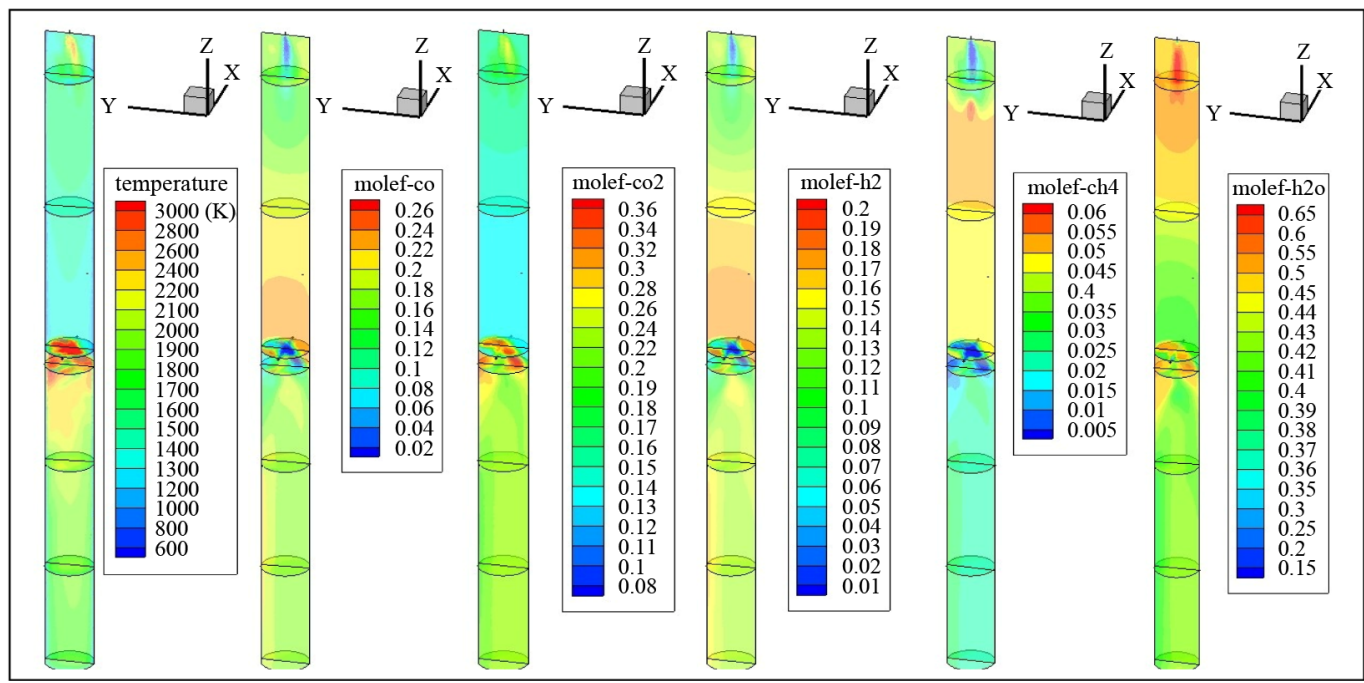

Figure 5. CFD simulated gas temperature and species mole fraction distributions for Case 6 (60\% - 40\% for oxygen distribution). 


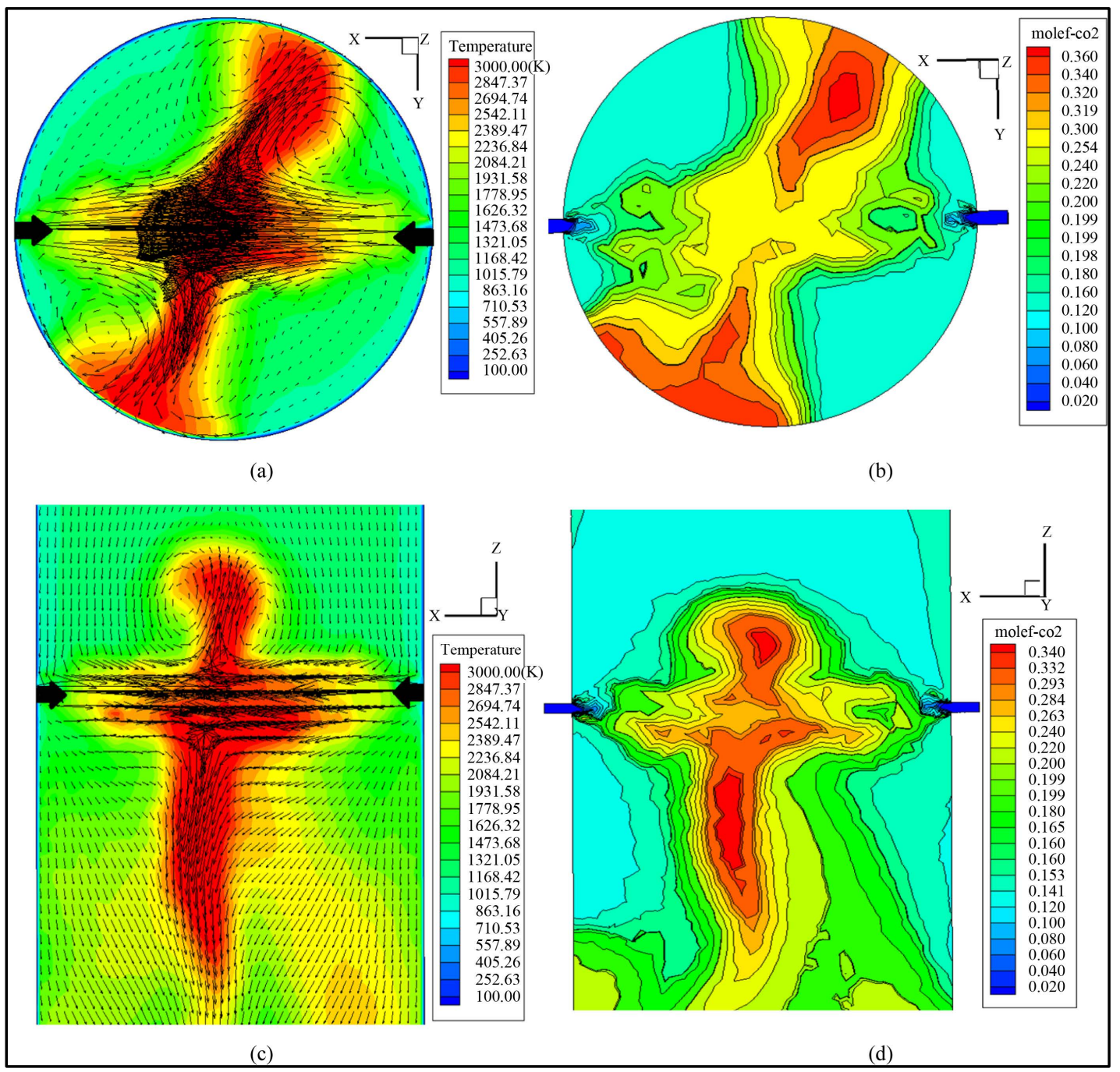

Figure 6. CFD cross-sectional and mid-plane plots of velocity vector, contours of temperature and mole fraction of $\mathrm{CO}_{2}$ for Case 6 (60\% - 40\% for oxygen distribution). (a) Cross-sectional temperature contour and velocity vector at the second injection. (b) Cross-sectional mole fraction of $\mathrm{CO}_{2}$ at the second injection. (c) Mid-plane temperature contour and velocity vector near second injection. (d) Mid-plane mole fraction of $\mathrm{CO}_{2}$ near second injection.

\subsection{Effect of Oxygen Injection Distribution under the Experimental Condition (Operating Pressure: 2.5 Bars, $\mathbf{0}_{2}$ : 0.6 of Stoichiometric Amount)}

To investigate the effect of different oxygen-distribution feeding schemes on the gasification performance under the low operating pressure condition, seven computational simulations cases corresponding to the experimental conditions (operating pressure: 2.5 bars, $\mathrm{O}_{2}$ : 0.6 of stoichiometric amount for complete combustion) are conducted with the oxygen fed from top at $100 \%, 90 \%, 80 \%, 70 \%, 60 \%, 50 \%$, and $40 \%$ respectively. These cases are numbered from Case 2 to Case 8 as shown in Table 3. The CFD results of these 7 cases are shown in Table 5, including the syngas composition at the exit, the syngas temperature at four locations $\left(\mathrm{T}_{\text {exit }}=\mathrm{TE}-300-4, \mathrm{~T} 2=\right.$ TE-300-8, T3 = TE-300-12, T4 = TE-300-13), carbon conversion ratio (CCR), and the higher heating value (HHV). The comparisons between CFD results and experimental data are shown graphically in Figure 9. The variations of simulated syngas compositions for different cases are shown in Figure 10.

Figure 9 shows that the experimental data and the CFD results yield the same trend of change for temperature distribution at the exit as the oxygen feeding distribution changes between two stages. When the percentage of oxygen injected from top reduces from $100 \%$ to $40 \%$, the temperature decreases at the first stage (T4 and T3) 


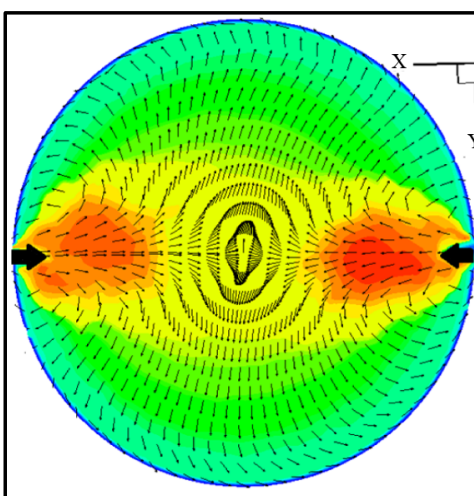

(a)

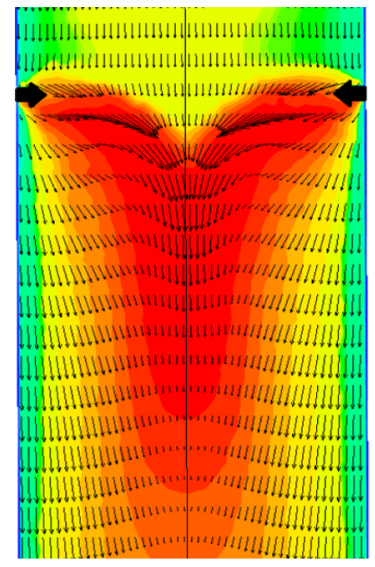

(c)

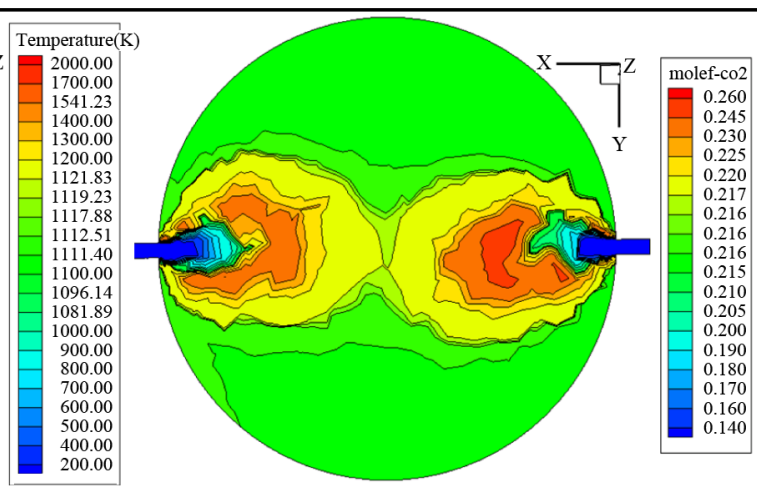

(b)
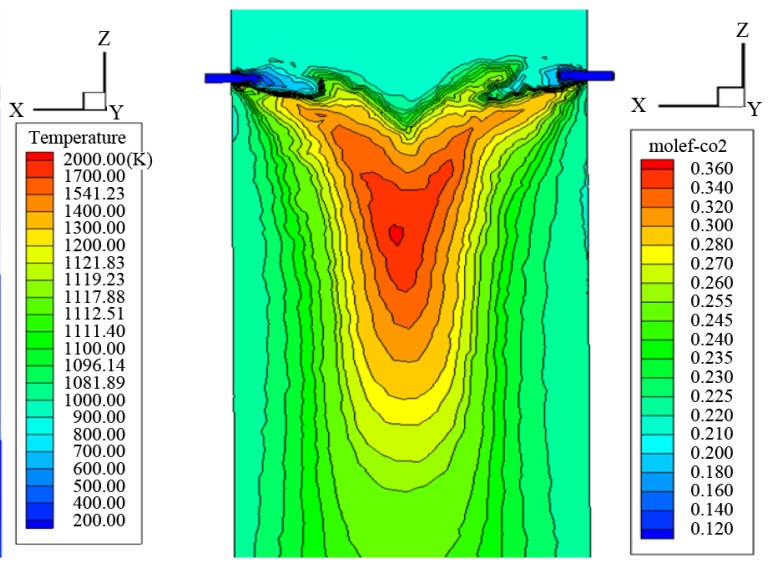

(d)

Figure 7. Cross-sectional and mid-plane plots of velocity vector, contours of temperature and mole fraction of $\mathrm{CO}_{2}$ at second injection for Case 3 (90\% - 10\% for oxygen distribution). (a) Cross-sectional temperature contour and velocity vector at the second injection. (b) Cross-sectional mole fraction of $\mathrm{CO}_{2}$ at the second injection. (c) mid-Plane temperature contour and velocity vector second injection. (d) Mole fraction of $\mathrm{CO}_{2}$ at the second injection.
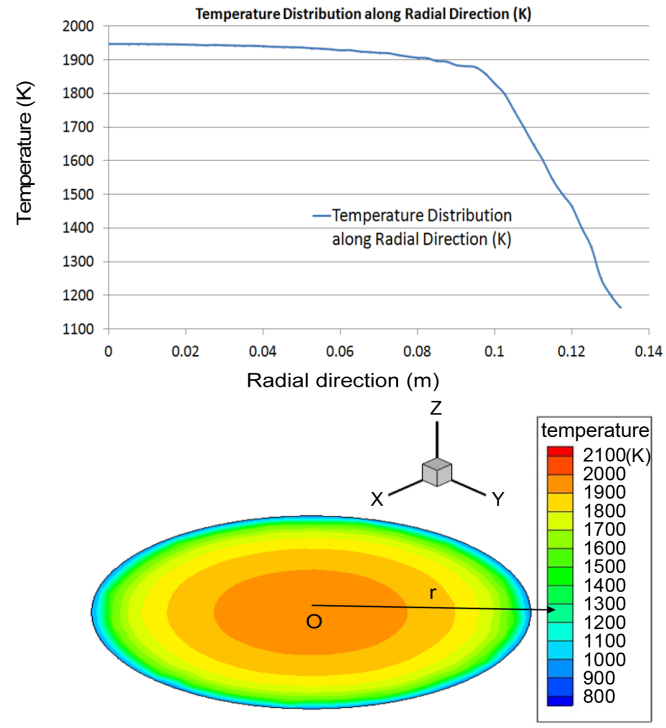

Figure 8. Gas temperature distribution at exit cross-sectional plane of the gasifier for Case 6 (60\% $40 \%$ oxygen distribution). 


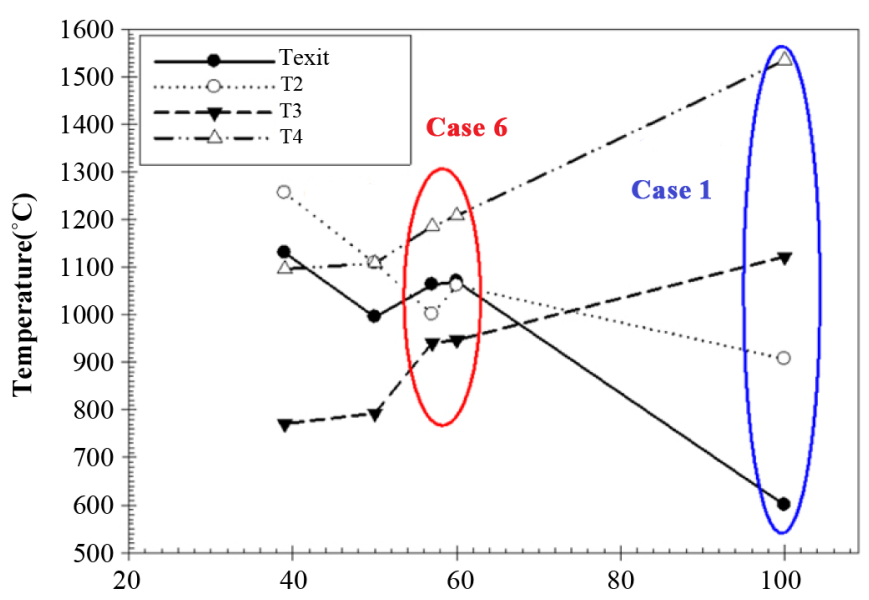

(a)

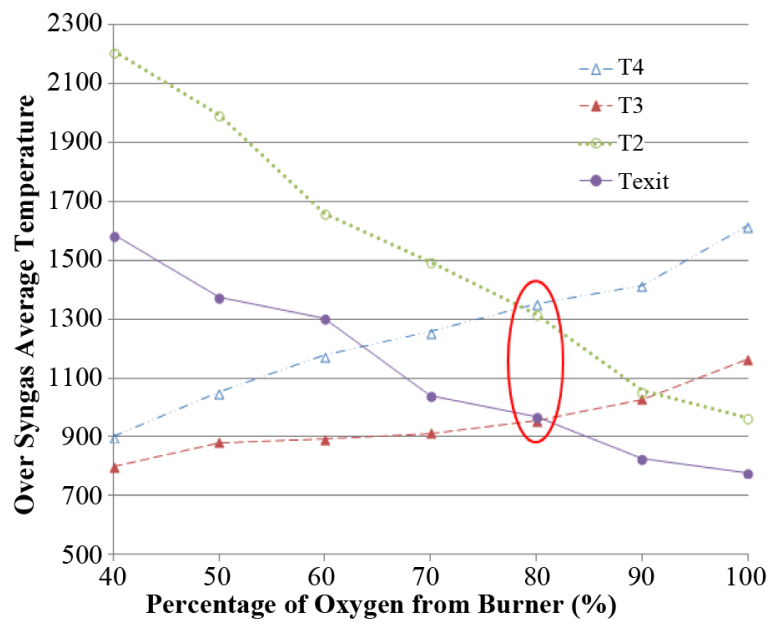

(b)

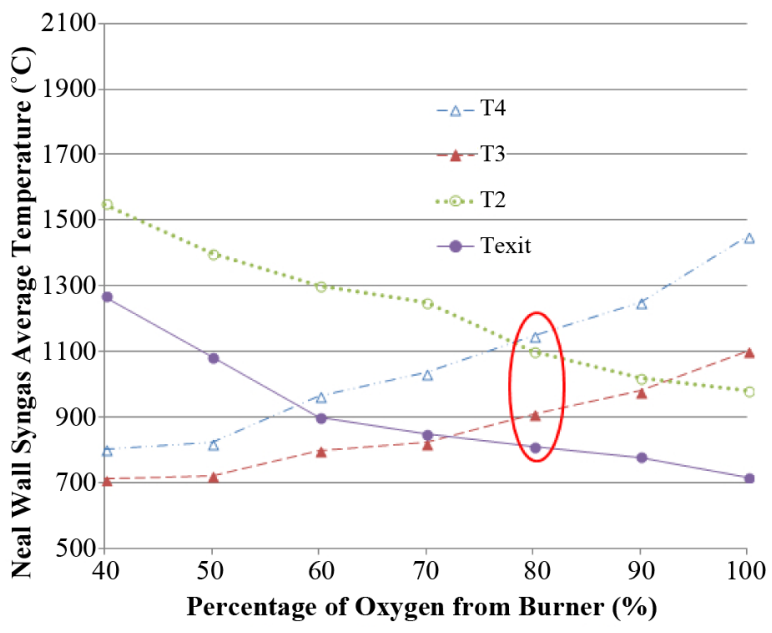

(c)

Figure 9. The effect of two-stage oxygen injection distribution on the gasifier wall temperature (a) experimental data (in wall cavities); (b) CFD results of mass-flow weighted syngas exit temperature; (c) CFD results for near-wall temperature (5 $\mathrm{mm}$ to the wall) for Cases 2 to 8 (Note: $\mathrm{T}_{\text {exit, }}$ T2, T3, and T4 in this figure correspond to TE-300-4, 8, 12, and 13 in Figure 1).

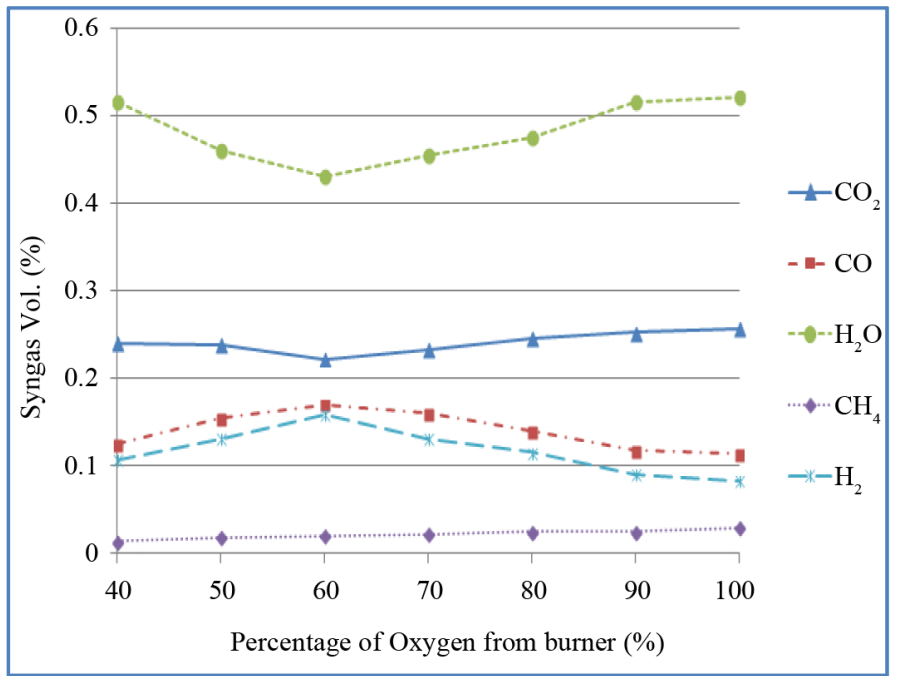

Figure 10. CFD simulated effect of two-stage oxygen injection distribution on the syngas composition for Cases 2 to 8. 
Table 5. CFD results of syngas compositions, syngas temperatures at different locations, carbon conversion ratio, and HHV for Cases 2 to 8 . $\mathrm{T}_{\text {exit, plane }}$ is the mass flow weighted average over the cross-section of the exit plane. $\mathrm{T}_{\text {exit. near wall }}$ is the circumferential average temperature at $5 \mathrm{~mm}$ from the wall.

\begin{tabular}{cccccccc}
\hline $\mathrm{O}_{2}$ distribution & Case 2 & Case 3 & Case 4 & Case 5 & Case 6 & Case 7 & Case 8 \\
& $100 \%-0 \%$ & $90 \%-10 \%$ & $80 \%-20 \%$ & $70 \%-30 \%$ & $60 \%-40 \%$ & $50 \%-50 \%$ & $40 \%-60 \%$ \\
\hline $\mathrm{CO}_{2}(\mathrm{Vol})$ & 0.256 & 0.252 & 0.245 & 0.233 & 0.222 & 0.238 & 0.240 \\
$\mathrm{CO}(\mathrm{Vol})$ & 0.113 & 0.117 & 0.140 & 0.160 & 0.170 & 0.154 & 0.125 \\
$\mathrm{H}_{2} \mathrm{O}(\mathrm{Vol})$ & 0.520 & 0.516 & 0.475 & 0.455 & 0.430 & 0.460 & 0.515 \\
$\mathrm{H}_{2}(\mathrm{Vol})$ & 0.082 & 0.090 & 0.115 & 0.130 & 0.158 & 0.130 & 0.107 \\
$\mathrm{CH}_{4}(\mathrm{Vol})$ & 0.029 & 0.025 & 0.025 & 0.022 & 0.020 & 0.018 & 0.013 \\
$\mathrm{~T} 4(\mathrm{~K})$ & 1892 & 1689 & 1627 & 1530 & 1450 & 1325 & 1174 \\
$\mathrm{~T} 3(\mathrm{~K})$ & 1439 & 1301 & 1228 & 1186 & 1164 & 1154 & 1071 \\
$\mathrm{~T} 2(\mathrm{~K})$ & 1237 & 1329 & 1590 & 1769 & 1934 & 2267 & 2484 \\
$\mathrm{~T}_{\text {exit plane }}(\mathrm{K})$ & 1052 & 1101 & 1242 & 1314 & 1550 & 1647 & 1859 \\
$\mathrm{~T}_{\text {exit, near wall }}(\mathrm{K})$ & 992 & 1052 & 1084 & 1124 & 1172 & 1356 & 1542 \\
$\mathrm{CCR}$ & $72.90 \%$ & $74.62 \%$ & $85.86 \%$ & 93.02 & $98.88 \%$ & $99.22 \%$ & $99.94 \%$ \\
$\mathrm{HHV}(\mathrm{kJ} / \mathrm{kmol})$ & 73,180 & 78,455 & 97,559 & 110,776 & 127,713 & 109,078 & 89,284 \\
\hline
\end{tabular}

and increases at the second stage ( $\mathrm{T} 2$ and $\left.\mathrm{T}_{\text {exit }}\right)$. This is because if less oxygen is injected from the top, then less char will go through the exothermic combustion process and less combustion heat is released. At the first glance, the variation trends appear to reverse around $60 \%$ - 50\%. Therefore, the analysis and explanations are separated into two parts based on the oxygen distribution on the top: $100 \%$ - $60 \%$ vs. $60 \%$ - $40 \%$. The CFD simulated syngas compositions are used to provide explanation of the variations of near-wall temperature distributions.

$100 \%-60 \%$ top $\mathrm{O}_{2}$ injection-Figure 10 shows that CFD simulated mole fractions of $\mathrm{CO}$ and $\mathrm{H}_{2}$ at the exit increase when the top injected oxygen reduces from $100 \%$ to $60 \%$, but they reduce when the top injected oxygen decreases from $60 \%$ to $40 \%$. The mole fraction of $\mathrm{CO}_{2}$ has an opposite changing trend.

$60 \%-40 \%$ top $\mathrm{O}_{2}$ injection-If the mass fraction of top injected oxygen continues to reduce below $60 \%$, there is more unburned char going though the gasification process (mainly $\mathrm{C}+1 / 2 \mathrm{CO}_{2} \rightarrow \mathrm{CO}, \mathrm{C}+\mathrm{H}_{2} \mathrm{O} \rightarrow \mathrm{CO}+\mathrm{H}_{2}$ ), resulting in more production of $\mathrm{CO}$ and $\mathrm{H}_{2}$ at the first stage. At the second injection stage, some of the injected oxygen reacts with $\mathrm{CH}_{4}$ to produce $\mathrm{CO}$ and $\mathrm{H}_{2}$. Therefore, the total amount of $\mathrm{CO}$ and $\mathrm{H}_{2}$ increases and $\mathrm{CO}_{2}$ decreases at the exit of gasifier. However, if more than $40 \%-50 \%$ of the total oxygen is injected from the second injection location, more $\mathrm{CO}$ and $\mathrm{H}_{2}$, which were produced through the gasification process at the first stage, react with the oxygen through the combustion process at the second stage and result in more $\mathrm{CO}_{2}$ and $\mathrm{H}_{2} \mathrm{O}$. Therefore, as indicated in Figure 10, $\mathrm{CO}$ and $\mathrm{H}_{2}$ decrease and $\mathrm{CO}_{2}$ and $\mathrm{H}_{2} \mathrm{O}$ increase at the exit of the gasifier when the portion of oxygen injected from the top is reduced from $60 \%$ to $40 \%$ based on the CFD results

Meanwhile, the carbon conversion ratio increases, and the exit mole fraction of $\mathrm{CH}_{4}$ reduces when the percentage of oxygen injected from the top reduces from $100 \%$ to $40 \%$. The reason for this trend is that the unburned char and $\mathrm{CH}_{4}$ react with oxygen through $\mathrm{C}+1 / 2 \mathrm{O}_{2} \rightarrow \mathrm{CO}$ and $\mathrm{CH}_{4}+1 / 2 \mathrm{O}_{2} \rightarrow \mathrm{CO}+2 \mathrm{H}_{2}$ at the second injection stage. When oxygen injected from the second stage increases beyond $40 \%$, the carbon conversion ratio reaches $99 \%$.

One of the advantages of employing the two-stage oxygen control is to reduce the wall temperature gradient, and hence, the thermal stress along the gasifier can be reduced. The experimental results in Figure 9(a) show that the overall near-wall temperature difference in the gasifier is reduced to a narrower range of $900^{\circ} \mathrm{C}-1200^{\circ} \mathrm{C}$ (with a $60 \%-40 \%$ two-stage oxygen injection split) from a wider range of $600^{\circ} \mathrm{C}-1500^{\circ} \mathrm{C}$ (with $100 \%$ top injection). In contrast, the CFD result in Figure 9(b) shows that the case of $80 \%-20 \%$ yields the most uniform syngas temperature within a range from $955^{\circ} \mathrm{C}$ to $1354^{\circ} \mathrm{C}$, while the case of $60 \%-40 \%$ in Table 5 yields the highest syngas HHV $(127,713 \mathrm{~kJ} / \mathrm{kmole})$. The case of $80 \%-20 \%$ yields the lowest peak temperature and the most uniform syngas temperature within a range from $810^{\circ} \mathrm{C}$ to $1150^{\circ} \mathrm{C}$. No experimental data are available for comparing the $80 \%-20 \%$ CFD case. 


\subsection{Effect of Oxygen Injection Distribution under High Operating Pressure Condition (25 Bars with $40 \%$ of Stoichiometric $\mathrm{O}_{2}$ )}

Since most of the gasifiers are operated under the condition with high pressures above 25 bars and low sub-stochiometric oxygen feeding below $40 \%$, the rest of the analysis will be focused on presenting the CFD simulation at a high pressure (25 bars) and low oxygen stoichiometric ratio (0.4). In total, four cases (Cases 9 to 12 as listed in Table 3) have been conducted.

Simila to the discussion in section 4.2, the syngas composition and temperature at different locations, CCR and HHV for Cases 9 - 12 are provided in Table 6, Figure 11 and Figure 12 respectively. The results are summarized below.

1) Compared to the results of the low operating pressure cases, the carbon conversion rates for different oxygen injection distribution are all above 95\% in high operating pressure cases. Two mechanisms are considered to contribute to this higher carbon conversion rate: a) The partial pressure of the $\mathrm{CO}_{2}, \mathrm{H}_{2} \mathrm{O}$, and even $\mathrm{O}_{2}$ increases by a factor of 10 . The char reaction rate expression contains the partial pressure of these gases at the coal particle surface, so the char conversion rate (mass per time) increases notably as the operating pressure increases. b) The longer particle residence time could also contribute to achieving a higher carbon conversion ratio. The average residence time is about 6 - 7 seconds for the high pressure cases while it is 3 - 4 seconds for the low-pressure cases.

2) Both the high operating pressure and low pressure cases follow the same trend of change of exit average

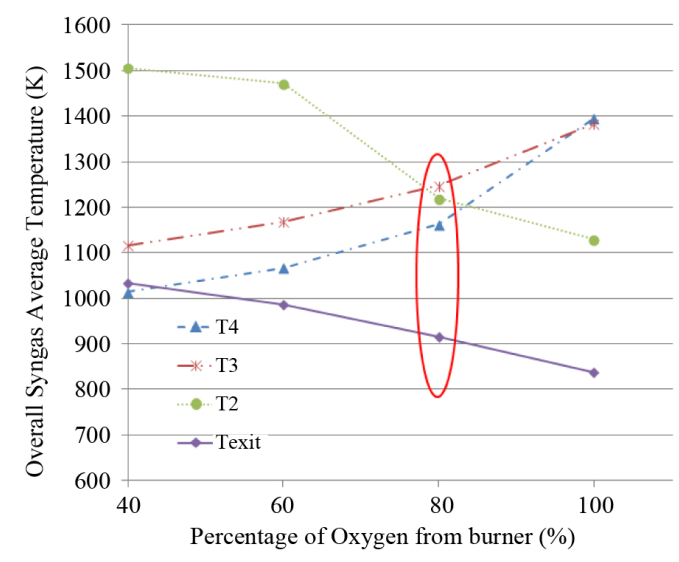

(a)

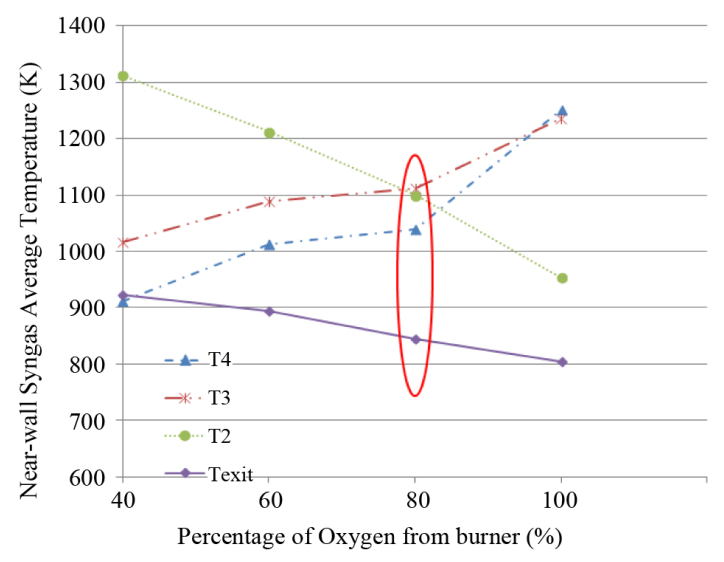

(b)

Figure 11. CFD simulated effect of two-stage oxygen injection distribution on the mass flow weighted syngas temperature at high pressure (25 bars) for Cases 9 to 12. (Note: The temperature locations $\mathrm{T}_{\text {exit, }} \mathrm{T} 2, \mathrm{~T} 3$, T4 in this figure correspond to TE-300-4, 8, 12, and 13 in Figure 1). (a) Average cross-sectional temperature. (b) Average near-wall temperature.

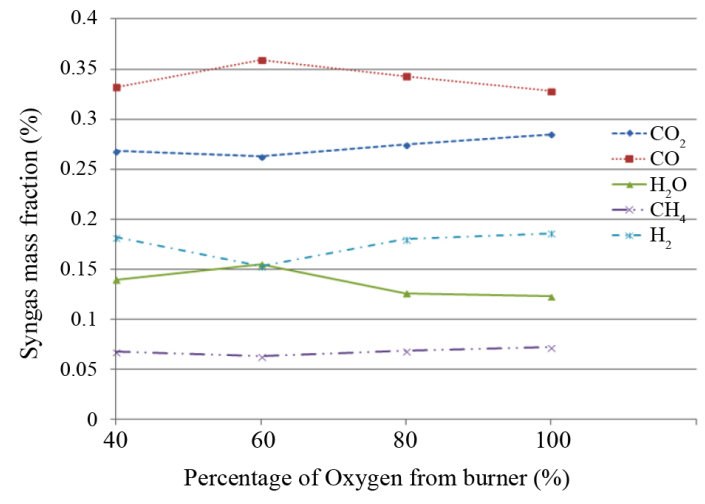

(a)

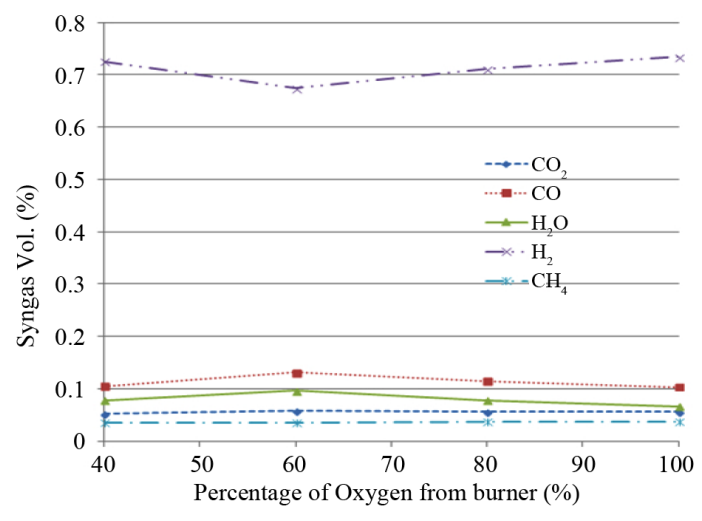

(b)

Figure 12. CFD simulated effect of two-stage oxygen injection distribution on the syngas composition at high pressure (25 bars) for Cases 9 to 12. (a) Mass fraction. (b) Volume fraction. 
Table 6. CFD predicted syngas conditions at 25 bars for Cases 9 to 12.

\begin{tabular}{ccccc}
\hline $\mathrm{O}_{2}$ distribution & Case $9100 \%-0 \%$ & Case $1080 \%-20 \%$ & Case $1160 \%-40 \%$ & Case $1240 \%-60 \%$ \\
\hline $\mathrm{CO}_{2}$ Vol (Mass) & $0.056(0.285)$ & $0.057(0.275)$ & $0.059(0.263)$ & $0.053(0.268)$ \\
$\mathrm{CO}$ Vol (Mass) & $0.103(0.328)$ & $0.115(0.343)$ & $0.131(0.359)$ & $0.105(0.332)$ \\
$\mathrm{H}_{2} \mathrm{O}$ Vol (Mass) & $0.067(0.123)$ & $0.078(0.126)$ & $0.097(0.155)$ & $0.078(0.140)$ \\
$\mathrm{H}_{2}$ Vol (Mass) & $0.734(0.186)$ & $0.712(0.180)$ & $0.674(0.153)$ & $0.726(0.182)$ \\
$\mathrm{CH}_{4}$ Vol (Mass) & $0.037(0.072)$ & $0.037(0.069)$ & $0.036(0.063)$ & $0.035(0.068)$ \\
$\mathrm{T} 4(\mathrm{~K})$ & 1395 & 1162 & 1067 & 1014 \\
$\mathrm{~T} 3(\mathrm{~K})$ & 1383 & 1247 & 1169 & 1116 \\
$\mathrm{~T} 2(\mathrm{~K})$ & 1129 & 1220 & 1472 & 1506 \\
$\mathrm{~T}_{\text {exit Plane }}(\mathrm{K})$ & 838 & 915 & 986 & 922 \\
$\mathrm{~T}_{\text {exit, near wall }}(\mathrm{K})$ & 804 & 845 & 894 & $99.97 \%$ \\
$\mathrm{CCR}$ & $99.99 \%$ & $95.34 \%$ & $98.88 \%$ & 395,495 \\
$\mathrm{HHV}(\mathrm{kJ} / \mathrm{kmol})$ & 392,295 & 391,271 & 376,653 & 1033 \\
\hline
\end{tabular}

temperature as the oxygen feeding distribution changes between two stages.

3) Consistent with the low pressure cases, the changing trend of syngas composition reverses at the $60 \%-40 \%$ case. The $80 \%$ - 20\% case produces the lowest peak temperature and most uniform temperature in the gasifier, but with the lowest CCR.

4) As more oxygen is injected at the second stage, $\mathrm{CO}$ and $\mathrm{CO}_{2}$ have the same trend of change as in the low pressure condition; however, $\mathrm{H}_{2} \mathrm{O}$ and $\mathrm{H}_{2}$ change in the opposite direction.

5) The major differences between the high and the low pressure cases are: a) the average temperature is much lower at each corresponding location in the 25 bars condition; b) $\mathrm{H}_{2}$ dominates the syngas composition (about $70 \%$ vol.) at 25 bars case.

6) The $40 \%$ - 60\% case produces the syngas with the highest HHV in the 25 bar case vs. $60 \%-40 \%$ case in the 2.5 bars cases, but with the highest peak wall temperature.

\section{Conclusions}

1) The experiments at 2.5 bars show the $60 \%$ - $40 \%$ oxygen distribution yields the most uniform wall temperature along the gasifier.

2) In cases of split two-stage oxygen injections from $100 \%$ to $40 \%$ with 0.6 stoichiometric oxygen at 2.5 bars, the CFD predicts a) the similar trend of changing temperature as in the experimental data; b) the $80 \%-20 \%$ case yields the lowest peak temperature and the most uniform gas temperature distribution along the gasifier; and c) the $60 \%$ - $40 \%$ case produces the syngas with the highest HHV.

3) The CFD's prediction of the effect of oxygen distribution under 25 bars operating pressure case shows that a) the carbon conversion ratio for different oxygen injection schemes are all above 95\%; b) $\mathrm{H}_{2}$ (about $70 \%$ vol.) dominates the syngas composition at exit; c) same as in the 2.5 bar cases, the $80 \%$ - $20 \%$ case yields the lowest peak temperature and most uniform gas temperature distribution along the gasifier; and d) the $40 \%-60 \%$ case produces the syngas with the highest HHV.

4) Chemical reactions are affected by the local flow behavior. Strong opposing injection of oxygen at second stage squeezes the main flow laterally on the vertical planes perpendicular to the injection direction, making combustion spread accordingly in the vertically plane at the second stage.

Both experimental data and CFD predictions verify the hypothesis that it is feasible to reduce the peak temperature and achieve more uniform temperature in the gasifier by adequately controlling two-stage oxygen injection with only minor changes of CCR and HHV under the high-pressure (25 bars) condition. However, the variations of CCR and HHV are notable under the low pressure (2.5 bars) condition.

After this study was completed, we realized that Tsinghua University in China has already successfully developed an oxygen-staged gasifier [15]. One of the merits claimed by the Tsinghua research group was that the 
oxygen-staged scheme helped to reduce the syngas temperature and thus significantly extends the fuel injector's life expectancy. It appears that the success of Tsinghua's oxygen-stage scheme supports the hypothesis of this study. Since no detailed technical information has been released by Tsinghua, the information generated by this study from both experiments and CFD simulation are considered to be useful reference to the gasification community.

\section{Acknowledgements}

This study was partially supported by the Louisiana Governor's Energy Initiative via the Clean Power and Energy Research Consortium (CPERC) administered by the Louisiana Board of Regents. The ITRI gasifier was funded by the Taiwan Bureau of Energy.

\section{References}

[1] Wang, T., Silaen, A., Hsu, H.W. and Shen, C.H. (2010) Investigation of Heat Transfer and Gasification of Two Different Fuel Injectors in an Entrained-Flow Gasifier. ASME Journal of Thermal Science and Engineering Applications, 2, 011001/1-10.

[2] Wang, T., Lu, X., Hsu, H.W. and Shen, C.H. (2011) Investigation of the Performance of Syngas Quench Cooling Design in a Downdraft Entrained Flow Gasifier. Proceedings of the 28th International Pittsburgh Coal Conference, Pittsburgh, 12-15 September 2011, 1-18.

[3] Smoot, L.D. and Smith, PJ. (1985) Coal Combustion and Gasification. Plenum Press, New York. http://dx.doi.org/10.1007/978-1-4757-9721-3

[4] Chen, C., Horio, M. and Kojima, T. (2000) Numerical Simulation of Entrained Flow Coal Gasifiers. Chemical Engineering Science, 55, 3861-3833. http://dx.doi.org/10.1016/S0009-2509(00)00030-0

[5] Westbrook, C.K. and Dryer, F.L. (1981) Simplified Reaction Mechanisms for the Oxidation of Hydrocarbon Fuels in Flames. Combustion Science and Technology, 27, 31-43.

[6] Jones, W.P. and Lindstedt, R.P. (1988) Global Reaction Schemes for Hydrocarbon Combustion. Combustion and Flame, 73, 233. http://dx.doi.org/10.1016/0010-2180(88)90021-1

[7] Benyon P. (2002) Computational Modelling of Entrained Flow Slagging Gasifiers. PhD Thesis, School of Aerospace, Mechanical \& Mechatronic Engineering. University of Sydney, Sydney.

[8] Lu, X. and Wang, T. (2013) Water-Gas Shift Modeling in Coal Gasification in an Entrained-Flow Gasifier Part 1: Development of Methodology and Model Calibration. Fuel, 108, 629-638.

[9] Lu, X. and Wang, T. (2013) Water-Gas Shift Modeling in Coal Gasification in an Entrained-Flow Gasifier Part 2: Gasification Application. Fuel, 108, 620-628.

[10] Silaen, A. and Wang, T. (2010) Effect of Turbulence and Devolatilization Models on Gasification Simulation. International Journal of Heat and Mass Transfer, 53, 2074-2091. http://dx.doi.org/10.1016/j.ijheatmasstransfer.2009.12.047

[11] Fletcher, T.H., Kerstein, A.R., Pugmire, R.J. and Grant, D.M. (1990) Chemical Percolation Model for Devolatilization: 2. Temperature and Heating Rate Effects on Product Yields. Energy and Fuels, 4, 54-60. http://dx.doi.org/10.1021/ef00019a010

[12] Fletcher, T.H. and Kerstein, A.R. (1992) Chemical Percolation Model for Devolatilization: 3. Direct Use of 13C NMR Date to Predict Effects of Coal Type. Energy and Fuels, 6, 414-431. http://dx.doi.org/10.1021/ef00034a011

[13] Grant, D.M., Pugmire, R.J., Fletcher, T.H. and Kerstein, A.R. (1989) Chemical Percolation of Coal Devolatilization Using Percolation Lattice Statistics. Energy and Fuels, 3, 175-186. http://dx.doi.org/10.1021/ef00014a011

[14] Kobayashi, H., Howard, J.B. and Sarofim, A.F. (1976) Coal Devolatilization at High Temperatures. Symposium (International) on Combustion, 16, 411-425.

[15] Zhang, J. (2013) Innovativeness and Development of Tsinghua Gasification Technology. Gasification Technology Conference, Colorado Spring, 13-16 October 2013, 17 p. 
Scientific Research Publishing (SCIRP) is one of the largest Open Access journal publishers. It is currently publishing more than 200 open access, online, peer-reviewed journals covering a wide range of academic disciplines. SCIRP serves the worldwide academic communities and contributes to the progress and application of science with its publication.

Other selected journals from SCIRP are listed as below. Submit your manuscript to us via either submit@scirp.org or Online Submission Portal.
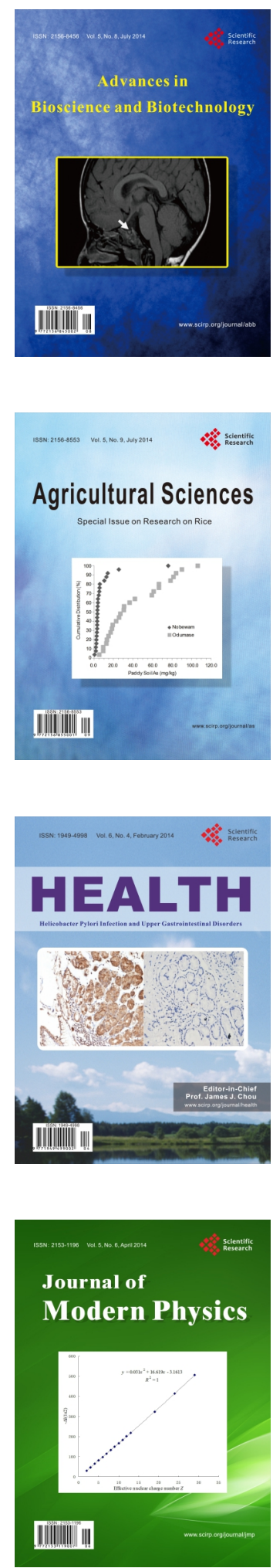
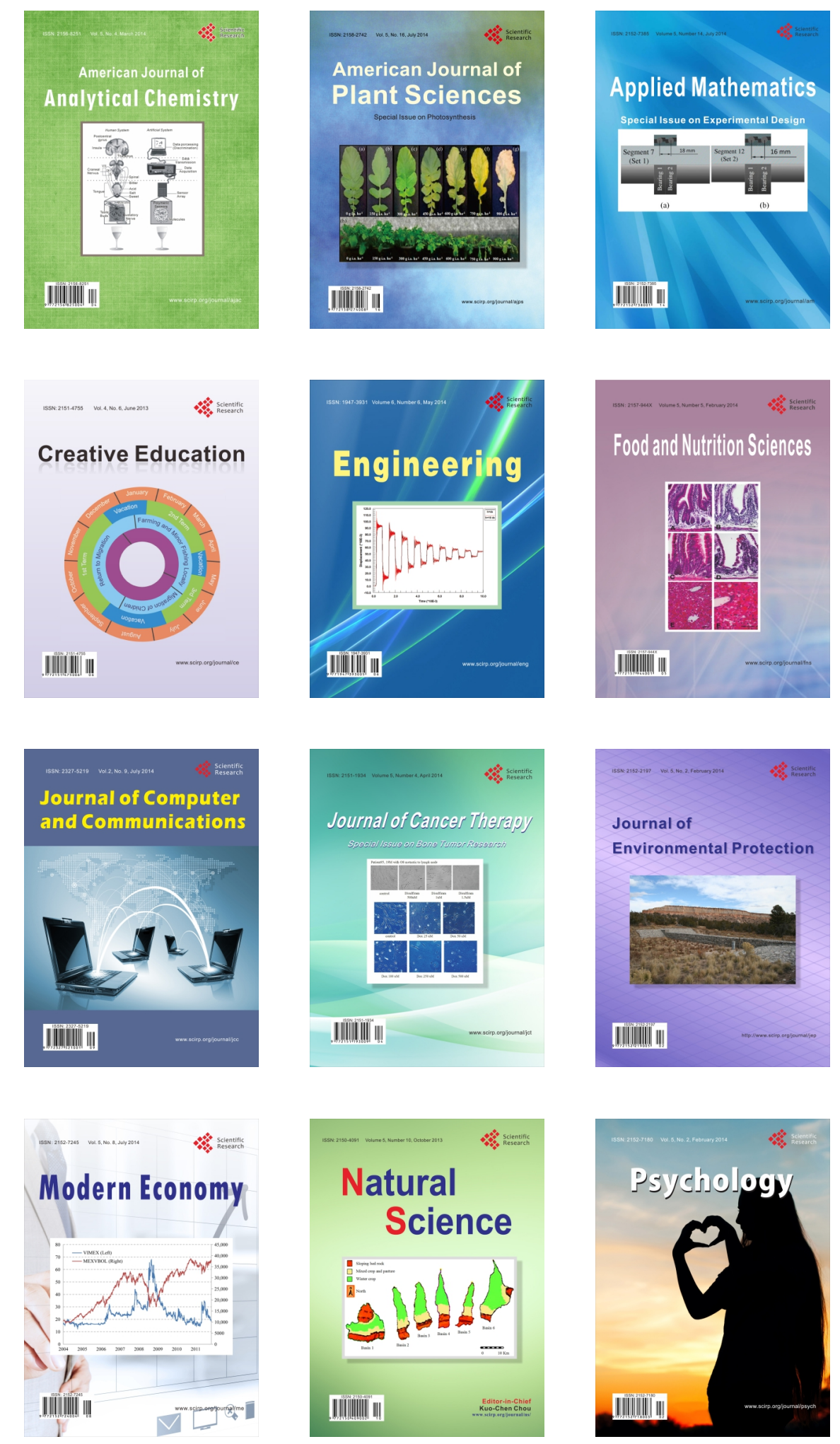